\title{
Aripiprazole in acute treatment of children and adolescents with autism spectrum disorder: a systematic review and meta-analysis
}

This article was published in the following Dove Press journal:

Neuropsychiatric Disease and Treatment

\author{
Narong Maneeton' \\ Benchalak Maneeton' \\ Suwannee Putthisri ${ }^{2}$ \\ Sirijit Suttajit' \\ Surinporn Likhitsathian' \\ Manit Srisurapanont ${ }^{\prime}$ \\ 'Department of Psychiatry, Faculty \\ of Medicine, Chiang Mai University, \\ Chiang Mai, Thailand; ${ }^{2}$ Department \\ of Psychiatry, Faculty of Medicine, \\ Ramathibodi Hospital, Mahidol \\ University, Bangkok, Thailand
}

Background: Recent randomized controlled trials indicated that aripiprazole was the effective treatment for children and adolescents with autism spectrum disorder (ASD).

Objective: This study systematically reviewed the efficacy, acceptability and tolerability of aripiprazole in treatment of ASD children and adolescents.

Data sources: Electronic search of databases including, Scopus, PubMed, CINAHL and Cochrane Controlled Trials Register was performed in July 2017.

Methods: The full-text versions of included trials were meticulously evaluated and extracted. The main efficacious outcomes consisted of pooled mean change scores of the standardized rating scales for ASD and the pooled response rate.

Results: A total of 408 randomized patients from eligible trials were included for synthesizing in this meta-analysis. The pooled mean change scores in aripiprazole-treated group for the Aberrant Behavior Checklist (ABC)-Irritability, ABC-Hyperactivity/noncompliance, ABCInappropriate speech and $\mathrm{ABC}$-Stereotypic behavior were significantly greater than those of the placebo-treated group. Unfortunately, the significant difference between two groups was not found for ABC-Lethargy/social withdrawal. The overall pooled response rate of the aripiprazole-treated group was significantly higher than that of the placebo-treated group. The pooled overall discontinuation rate in aripiprazole-treated group was significantly better than that of placebo-treated group. The pooled discontinuation rates due to adverse events in aripiprazole-treated group significantly differed from the placebo-treated group (RR [95\% CI] of $\left.1.43[0.65,3.18], I^{2}=0 \%\right)$.

Limitation: A small number of studies were gathered in this review.

Conclusion: Aripiprazole has efficacy in the treatment of behavioral disturbances, including irritability, hyperactivity/noncompliance, inappropriate speech and stereotypic behavior found in ASD children and adolescents; however, it could not improve the lethargy/social withdrawal in such patients. The present evidence also indicates that it is safe, acceptable and tolerable in such treatment. As a small sample size, further well-defined and large sample size studies should be conducted to warrant those findings.

Keywords: Aberrant Behavior Checklist, ABC, Children's Yale-Brown Obsessive Compulsive Scale, CY-BOCS, efficacy, acceptability, tolerability

\section{Introduction}

Autism spectrum disorder (ASD), considered as a neurodevelopmental disorder, has principal deficits in social communication and social interaction with restricted and repetitive patterns of behavior, interests and activities. A number of ASD children and adolescents also have additional difficulties, including aggressive and self-injurious 
behaviors, tantrums and irritability, frequently disturbing their education and development as well as creating a burden to caregivers. Several previous studies have explored effective therapy for behavioral difficulties in those children and adolescents.

Some studies illustrated the efficacy of a behavioral approach in aggressive and self-injurious behaviors, leading it to be a gold-standard treatment of such behavioral difficulties in ASDs. ${ }^{1}$ Unfortunately, those studies had some limitations, including the low quality of methodology, limited sample size or short-term treatment. ${ }^{1-3}$ In addition to personalized response for ASDs, the behavioral therapy regularly relies on a wide range of resources, which increases the cost. Therefore, such therapy may not be applied for all ASD children and adolescents. ${ }^{4}$ Other modalities may be an alternative treatment for those children and adolescents.

Several medications have been used in the treatment of behavioral problem, including antipsychotic drugs. ${ }^{5}$ Previous evidence has illustrated the effectiveness of antipsychotics in the treatments of ASD-related symptoms. ${ }^{6-9}$ Some studies suggest the efficacy of haloperidol in ASD children and adolescents. ${ }^{6,10}$ Such a high potency antipsychotic agent has potentially extrapyramidal side effects. ${ }^{5}$ Although risperidone, a serotonin-dopamine antagonist, has shown its efficacy in the treatment of ASD children and adolescents, it is associated with some adverse events, including somnolence, weight gain, dyskinesia and drooling. ${ }^{8,11-13}$ Other antipsychotic medications with a lower propensity of adverse events may be an alternative treatment in ASD children and adolescents.

Aripiprazole, a dopamine partial agonist, is mainly used in the treatment of schizophrenia ${ }^{14}$ and bipolar disorder. ${ }^{15}$ Recently, the evidence from randomized controlled trials (RCTs) suggests that it is also efficacious in treatment of irritability for ASD children and adolescents with well tolerability. ${ }^{9,16,17}$ Due to such RCTs including a small numbers of subjects, meta-analysis, known as a powerful method in determining the true effect size, can be applied to examine the efficacy, tolerability and acceptability of aripiprazole in the treatment of ASD children and adolescents. For this reason, this study was conducted to systematically review the efficacy, acceptability and tolerability of aripiprazole in children and adolescents with ASDs.

\section{Methods}

\section{Types of studies}

All RCTs of aripiprazole in ASD were considered for inclusion in this review.

\section{Types of participants}

Children and adolescents up to 18 years of age with any set of diagnostic criteria for ASD were considered in this review.

\section{Type of interventions}

Any aripiprazole treatment of ASD vs placebo in dose, form and frequency was eligible.

\section{Types of outcome measures}

1. The measured mean change scores of standardized rating scales for ASD

2. Response rate

3. Discontinuation rates

a. Overall discontinuation rate

b. Discontinuation rate due to adverse events

\section{Information sources}

Searching of the databases, including Scopus, PubMed, CINAHL and Cochrane Controlled Trials Register, was conducted. Because aripiprazole has been published in the PubMed since 1995, searching started from January 1995 to July 2017. Furthermore, searching of the ClinicalTrials.gov and European Union (EU) Clinical Trials Register was also carried out. All searches were restricted to human studies. The references of relevant articles gathered from any methods were inspected. All RCTs of aripiprazole treatment for child and adolescent ASD were entitled for this meta-analysis. Limitation of any language in RCTs was not applied.

\section{Searches}

In order to raise the sensitivity to optimally identify the RCTs, the strategic searches for the PubMed were restricted to the following words and phrases: [(aripiprazole) OR (Abilify)] AND [(Autism Spectrum Disorder) OR (Autistic Disorder) OR (Pervasive Developmental Disorder) OR (Asperger syndrome)]. This strategy was also applied for the other databases searched.

\section{Study selection}

All the titles and abstracts acquired from the electronic databases were assessed separately by two reviewers (NM and BM). After the full-text version of a relevant article was collected, two reviewers (NM and BM) individually evaluated whether it met eligible criteria. Consensus was applied in cases of disputes between reviewers.

\section{Data collection process}

Initially, the first reviewer (NM) extracted all the data from the full-version articles and study results of clinical trial 
register (if available). All extracted information was taken into the developed extraction. Finally, the second reviewer (BM) thoughtfully rechecked that data. Again, consensus was reached if a dispute occurred between two reviewers. In event of not reaching an agreement, the third reviewer (MS) made a decision.

\section{Data items}

The data extracted from RCTs had to consist of the following: 1) important outcomes for use to evaluate the quality of the individual study; 2) basic characteristics of each study associated with enrolled subjects, criterion diagnosis, study designs and criteria for eligibility/exclusion; 3) forms, doses and treatment duration of aripiprazole; 4) outcomes of interest; and 5) intention-to-treat outcomes.

\section{Risk of bias in individual studies}

Based on the Cochrane Collaboration's Tool for assessing risk of bias, all included RCTs' internal validity (quality) was determined by two reviewers (NM and BM). The risk of biases included sequence generation (randomization), allocation concealment, performance bias, incomplete outcome data, selective outcome reporting and other biases ${ }^{18}$ (Figure 1).

\section{Summary measures}

The main outcome measures were efficacy, acceptability and tolerability. The outcome efficacy was measured by the mean end point or the mean change scores of a standardized ASD rating scale and response rate measured on any set of criteria. The Aberrant Behavior Checklist (ABC) is one of the few empirically developed scales designed to measure psychiatric symptoms and behavioral disturbance exhibited by individuals with intellectual developmental disorder across various domains: Irritability (ABC-I); Hyperactivity/noncompliance (ABC-H); Inappropriate speech (ABC-IS); Stereotypic behavior (ABC-S); and Lethargy/social withdrawal (ABC$\mathrm{SW}) .{ }^{19,20}$ In consideration of a previous systematic review, acceptability was calculated by using the overall rate of discontinuation, ${ }^{21}$ while tolerability associated with adverse events of the treatments ${ }^{22}$ relied on the rate of discontinuation due to adverse events.

\section{Statistical analysis and synthesis of results}

In a systematic review, the continuous data are usually synthesized by using a weighted mean difference (WMD) or a standardized mean difference (SMD) with 95\% CI, calculated by the mean difference between the compared

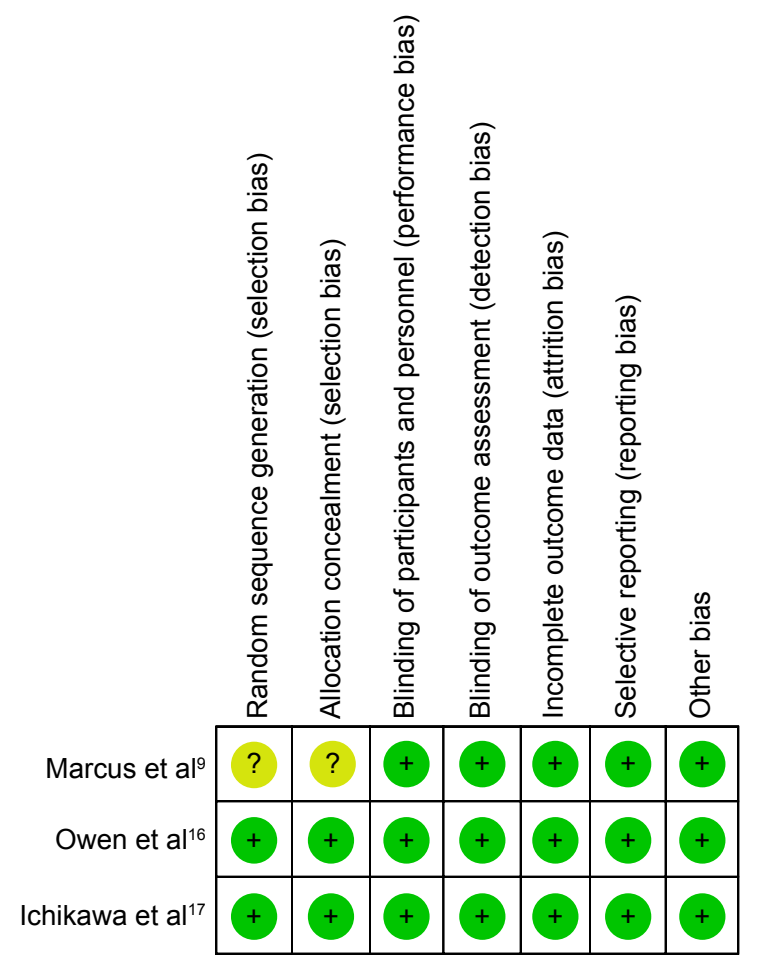

Figure I Summary of risk of bias in a clinical controlled trial of aripiprazole in children and adolescents with ASD.

Notes: Green circles indicate low risk of bias; yellow circles indicate unclear risk of bias.

Abbreviation: ASD, autism spectrum disorder.

groups divided by an estimate of the within-group SD. The WMD is a method of direct comparison or combination of the results gathered from a similar rating scale used across studies. Unfortunately, the WMD is not able to estimate the same outcomes that are measured by various rating scales across studies. For this reason, the SMD, not having a unit, is an alternative technique to compare or combine those outcomes. This systematic review was intended to estimate either the WMDs or the SMDs based on the measure scales used across studies. When the data such as SD were provided, the calculation was conducted by using the statistical methods or by direct substitution..$^{23}$ An inverse-variance, weighing the effect of individual study, was carried out to determine the pooled mean endpoint or change score with $95 \%$ CIs. $^{18}$

The relative risk (RR) with the 95\% CI was applied for synthesizing the dichotomous data. Therefore, comparison of pooled response and discontinuation rates were estimated by using the RRs with 95\% CI. The Mantel-Haenszel method was thoroughly used to evaluate all pooled RRs of discontinuous data with $95 \%$ CIs. ${ }^{18}$

As is known, synthesis of results in meta-analysis can be applied to the fixed or the random effect model. Based on 
the fixed effect model, the true effect size is assumed to be the same as in all eligible trials. Additionally, the summary effect is also the estimation of the common effect size in all studies. Although each eligible study is weighted, the result of the smaller study can be removed since the better outcomes regarding the same effect size in the larger ones are provided. In this event, a fixed effect model can be applied. However, the assumption of one true effect size is less likely to take place. Even if the all studies are comparatively homogenous, it may not be possible to conclude that they are completely identical. By this reason, a random effect model, expecting that the true effect size differs across studies, was allocated in all outcome synthesis. All outcomes were synthesized using the RevMan 5.3.

\section{Risk of bias across studies}

If possible, the evaluation of reporting bias would be determined by using a funnel plot, a simple scatter plot of the intervention effect estimated from individual studies against a measure of each study's size. When the plot resembled a symmetrical inverted funnel, one could estimate that the bias is possibly absent. ${ }^{24}$

\section{Test of heterogeneity}

To determine the similarities of clinical outcomes, a test of heterogeneity was applied in the present systematic review. Each outcome from an eligible study was examined to determine whether they were higher and different from the anticipated outcomes by chance alone. Evaluation of such results was performed by examining them from displayed graph and also using the test of heterogeneity. A significance of heterogeneity was defined as an $I^{2}$ of $50 \%$ or more.

\section{Results}

\section{Study selection}

A total of 356 citations were collected from searches of the databases $($ Scopus $=250$, PubMed=11, CINAHL $=57$, Cochrane Controlled Trials Register $=26$, ClinicalTrials. gov $=9$ and EU Clinical Trials Register=3) (Figure 2). Three hundred and fifteen citations remained after the duplicates were eliminated. Relying on assessments of the titles and abstracts from such those studies, six citations were gathered for evaluation in the full-text version. Of these six citations, three were disregarded from this review for the reason that one was a study of adult patients, ${ }^{25}$ one was a long-term study $^{26}$ and one was a post hoc analysis. ${ }^{27}$ Unfortunately, a relevant or unpublished study was not found. Consequently, a total of three articles were included in this review. ${ }^{9,16,17}$

\section{Study characteristics}

The study duration for all included studies was 8 weeks. Either aripiprazole or placebo was randomized for the participants. The response rate was defined as a reduction in ABC-I subscale score of at least 25\% and Clinical Global Impression-Improvement (CGI-I) score of 1 or 2 in all trials. The dose of aripiprazole was up to $15 \mathrm{mg}$ /day. All demographic and clinical characteristics between the two groups were well matched.

A total of 408 randomized patients from eligible trials were included for synthesizing in this meta-analysis. All patients met the autistic disorder criteria of the Diagnostic and Statistical Manual of Mental Disorders, fourth edition, text revision. Mean ages (SD) of participants for aripiprazole and placebo groups were 9.7 (3.2) and 9.6 (3.0) years, respectively. The basic characteristics of included studies are illustrated in Table 1.

All included studies reported the standardized measures, including ABC, CGI-I, CGI-Severity scale (CGI-S) scale and Children's Yale-Brown Obsessive Compulsive (CY-BOCS), therefore, the WMDs of the mean change scores for such measures could be used to estimate and synthesize such outcomes. Additionally, the response and discontinuation rates were illustrated in all included trials.

\section{Risk of bias within studies}

The included studies had a low risk for all risks of biases, except one. ${ }^{9}$ However, intention-to-treat analysis was not reported in all trials.

\section{Synthesis of results Efficacy}

According to the measurement of efficacy outcomes, a significance of heterogeneity occurred only in the pooled response rate, mean change score of $\mathrm{CY}$-BOC and mean end score of CGI-I. The pooled mean changed scores in aripiprazole-treated group for the $\mathrm{ABC}$-Irritability (I), ABC-Hyperactivity/noncompliance $(\mathrm{H}), \mathrm{ABC}$-Inappropriate speech (IS) and ABC-Stereotypic behavior (S) had significantly greater than that of the placebo-treated group with WMDs $(95 \% \mathrm{CI})$ of $-5.41(-7.58,-3.24), I^{2}=10 \%,-7.68$ $(-9.92,-5.45), I^{2}=0 \%,-1.23(-2.08,0.38), I^{2}=48 \%$, and $-2.04(-3.33,-0.74), I^{2}=47 \%$, respectively (Figures $\left.3-6\right)$. Unfortunately, the significant difference between two groups was not found in the ABC-SW (WMD [95\% CI] of -1.03 $[-2.69,0.62], I^{2}=0 \%$ ) (Figure 7 ). The overall pooled response rate of the aripiprazole-treated group was significantly higher than that of the placebo-treated group, with RR (95\% CI) of 


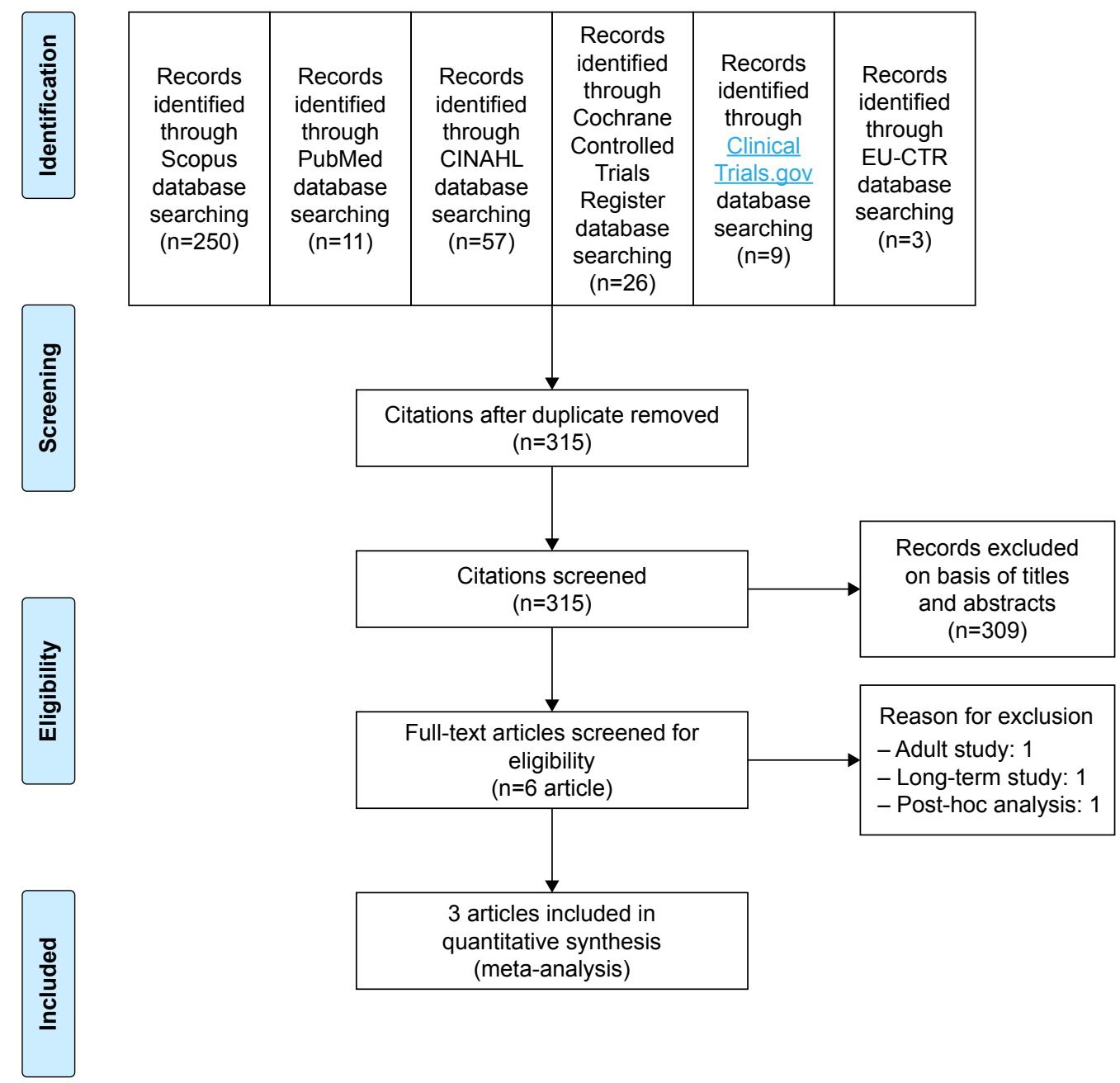

Figure 2 Flow of diagram of study,

Abbreviation: EU-CTR, European Union Clinical Trials Register.

$2.08(1.24,3.46), I^{2}=55 \%$ (Figure 8 ). Relying on such a rate of response, the number needed to treat (NNT) $(95 \% \mathrm{CI})$ was 3.7 (2.8, 5.7). Additionally, the mean change scores of the CGI-S and CY-BOC and mean end score of CGI-I were also significantly greater than those of the placebo-treated group with WMDs $(95 \% \mathrm{CI})$ of $-0.61(-0.85,-0.36), I^{2}=15 \%,-1.52$ $(-2.84,-0.20), I^{2}=67 \%$, and $-0.92(-1.31,-0.54), I^{2}=65 \%$, respectively (Figures 9-11).

\section{Main adverse events}

The pooled rates of extrapyramidal side effects and headache in the aripiprazole-treated and placebo-treated groups had no difference with RR $(95 \% \mathrm{CI})$ of $2.40(0.91,6.30), I^{2}=0 \%$, and $0.86(0.18,4.20), I^{2}=63 \%$, respectively. However, the pooled rate of sedation in the aripiprazole-treated group was significantly higher than placebo-treated group with RR $(95 \% \mathrm{CI})$ of $4.13(1.59,10.69), I^{2}=0 \%$. Although the pooled rates of decrease appetite were significantly higher in the aripiprazole-treated group and increase appetite was not different between two groups with RR (95\% CI) of $4.78(1.13,20.25), I^{2}=0 \%$, and $1.94(0.82,4.58), I^{2}=0 \%$, respectively, the weight mean change from baseline in aripiprazole-treated group was significantly higher than that in placebo-treated group with WMDs $(95 \% \mathrm{CI})$ of 0.97 (0.53, $1.40), I^{2}=0 \%$. The pooled incidence of subjects with fasting triglyceride $\geq 120 \mathrm{mg} /$ day for females and $\geq 160$ for males was not different between the two groups with RR (95\% CI) of $1.51(0.62,3.67), I^{2}=0 \%$. No subject experienced fasting serum glucose value $\geq 115 \mathrm{mg} / \mathrm{dL}$ in two studies, ${ }^{16,17}$ except one study ${ }^{9}$ found two patients (one treated with aripiprazole $10 \mathrm{mg}$ /day and another with $15 \mathrm{mg} /$ day). Considered in prolactin level, its pooled mean change in the aripiprazoletreated group more significantly decreased from baseline than that of placebo-treated group with WMDs (95\% CI) 
Table I The basic characteristics of randomized, controlled trials of aripiprazole vs placebo of autism spectrum disorder in children and adolescents

\begin{tabular}{|c|c|c|c|c|c|c|c|}
\hline Study & $\begin{array}{l}\text { Number of } \\
\text { randomized } \\
\text { patients }\end{array}$ & $\begin{array}{l}\text { Age of included } \\
\text { subjects } \\
\text { (years) }\end{array}$ & $\begin{array}{l}\text { Study } \\
\text { duration } \\
\text { (weeks) }\end{array}$ & Drug/dose & $\begin{array}{l}\text { Diagnostic } \\
\text { criteria }\end{array}$ & $\begin{array}{l}\text { Response } \\
\text { criteria }\end{array}$ & $\begin{array}{l}\text { Outcome } \\
\text { measures }\end{array}$ \\
\hline Marcus et $\mathrm{al}^{9}$ & 218 & $6-17$ & 8 & $\begin{array}{l}\text { Aripiprazole/ } \\
5,10,15 \mathrm{mg} / \text { day } \\
\text { (fixed dose) }\end{array}$ & $\begin{array}{l}\text { DSM-IV-TR } \\
\text { for autistic } \\
\text { disorder }\end{array}$ & $\begin{array}{l}\geq 25 \% \text { reduction } \\
\text { in the } A B C-I \\
\text { score and } C G I-I \\
\text { score }=\text { I or } 2\end{array}$ & $\begin{array}{l}\text { ABC } \\
\text { CGI-I } \\
\text { CGI-S } \\
\text { CGSQ } \\
\text { CY-BOCS } \\
\text { PedsQL }\end{array}$ \\
\hline Owen et al ${ }^{16}$ & 98 & $6-17$ & 8 & $\begin{array}{l}\text { Aripiprazole/up } \\
\text { to } 15 \mathrm{mg} / \text { day } \\
\text { (flexible dose) }\end{array}$ & $\begin{array}{l}\text { DSM-IV-TR } \\
\text { for autistic } \\
\text { disorder }\end{array}$ & $\begin{array}{l}\geq 25 \% \text { reduction } \\
\text { in the } A B C-I \\
\text { score and CGI-I } \\
\text { score }=I \text { or } 2\end{array}$ & $\begin{array}{l}\text { ABC } \\
\text { CGI-I } \\
\text { CGI-S } \\
\text { CGSQ } \\
\text { CY-BOCS } \\
\text { PedsQL }\end{array}$ \\
\hline Ichikawa et al ${ }^{17}$ & 92 & $6-17$ & 8 & $\begin{array}{l}\text { Aripiprazole/ } \\
\text { I, } 3,6,9,12, \\
15 \mathrm{mg} / \text { day } \\
\text { (flexible dose) }\end{array}$ & $\begin{array}{l}\text { DSM-IV-TR } \\
\text { for autistic } \\
\text { disorder }\end{array}$ & $\begin{array}{l}\geq 25 \% \text { reduction } \\
\text { in the } A B C-J-I \\
\text { score and CGI-I } \\
\text { score }=I \text { or } 2\end{array}$ & $\begin{array}{l}\text { ABC-J } \\
\text { CGAS } \\
\text { CGI-I } \\
\text { CGI-S } \\
\text { CY-BOCS }\end{array}$ \\
\hline
\end{tabular}

Note: Assessment scale.

Abbreviations: ABC, Aberrant Behavior Checklist; ABC-I, ABC-Irritability; ABC-J-I, Aberrant Behavior Checklist Japanese version in irritability subscale; CGAS, Children's Global Assessment Scale; CGI-I, Clinical Global Impression-Improvement; CGI-S, Clinical Global Impression-Severity; CGSQ, Caregiver Strain Questionnaire; CY-BOCS, Children's Yale-Brown Obsessive Compulsive Scale; DSM-IV-TR, Diagnostic and Statistical Manual of Mental Disorders, fourth edition, text revision; PedsQL, Pediatric Quality of Life Inventory.

of $-9.19(-13.83,-4.55), I^{2}=68 \%$ (Figure 12). No subject showed marked vital signs and electrocardiogram (ECG) abnormalities in both groups.

\section{Discontinuation rates}

Overall discontinuation rate (acceptability)

Heterogeneity was not significantly noted in the overall discontinuation rate. The pooled overall discontinuation rate in the aripiprazole-treated group was significantly better than that of the placebo-treated group (RR [ $95 \% \mathrm{CI}$ ] of 0.56 $\left.[0.36,0.88], I^{2}=0 \%\right)$.

Discontinuation rate due to adverse events (tolerability) Heterogeneity was not significantly illustrated in the discontinuation rate due to adverse events. The pooled discontinuation rates due to adverse events in the aripiprazole-treated group did not significantly differ from those in the placebo-treated group (RR [95\% CI] of $1.43[0.65,3.18], P^{2}=0 \%$ ).

\section{Risk of bias across studies}

As is known, if included studies in a systematic review have less than ten trials, evaluation of the publication bias by using a funnel plot may not have enough power to assess the chances of real asymmetry occurring due to the included outcomes. ${ }^{24}$ For this reason, the test of funnel plot could not be done due to limited included studies (three included trials).

\section{Discussion}

Based on the present review, aripiprazole is able to decrease irritability, hyperactivity/noncompliance, inappropriate

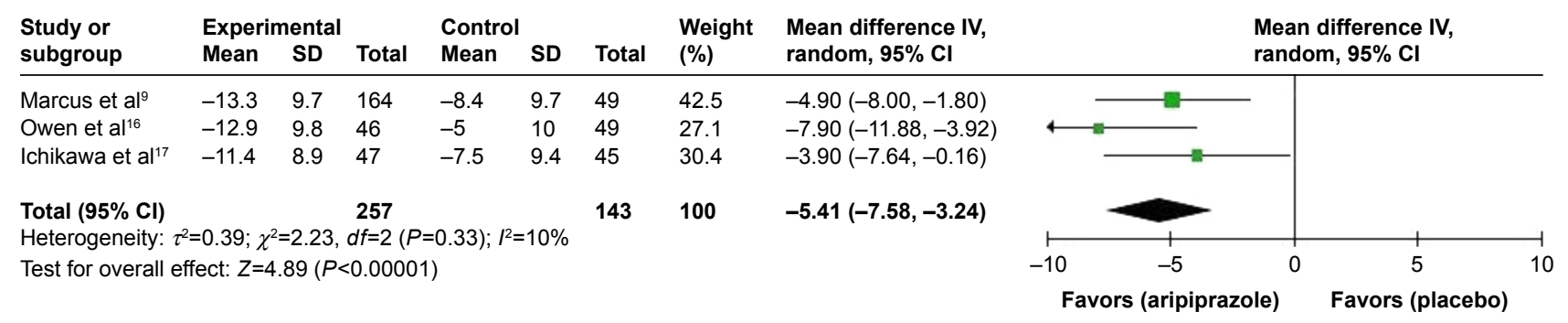

Figure 3 The forest plot of $A B C-I$ mean change scores from baseline $(95 \% \mathrm{Cl})$ of aripiprazole vs placebo in ASD in children and adolescents. Abbreviations: ABC-I, Aberrant Behavior Checklist-Irritability; ASD, autism spectrum disorder; df, degrees of freedom; IV, inverse variance. 


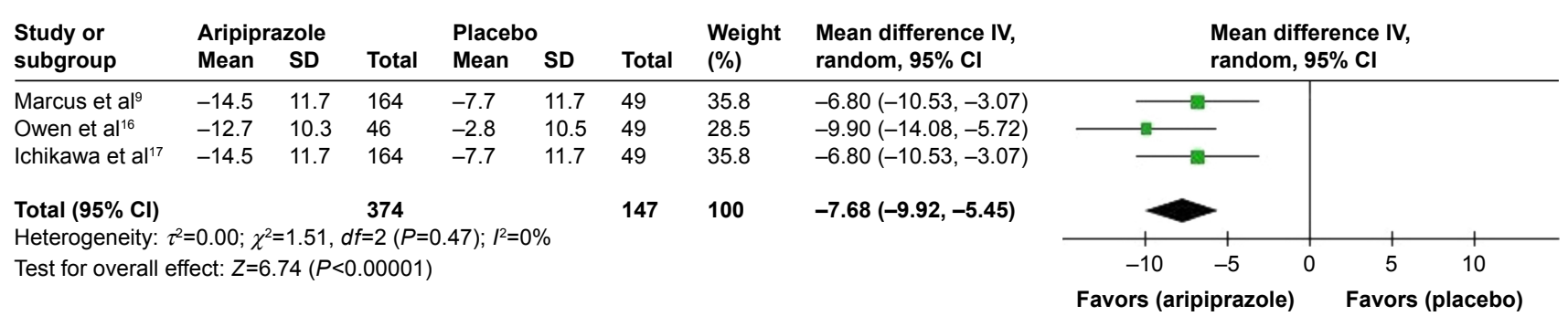

Figure 4 The forest plot of ABC-H mean change scores from baseline $(95 \% \mathrm{Cl})$ of aripiprazole vs placebo in ASD in children and adolescents.

Abbreviations: ABC-H, Aberrant Behavior Checklist-Hyperactivity/noncompliance; ASD, autism spectrum disorder; df, degrees of freedom; IV, inverse variance.

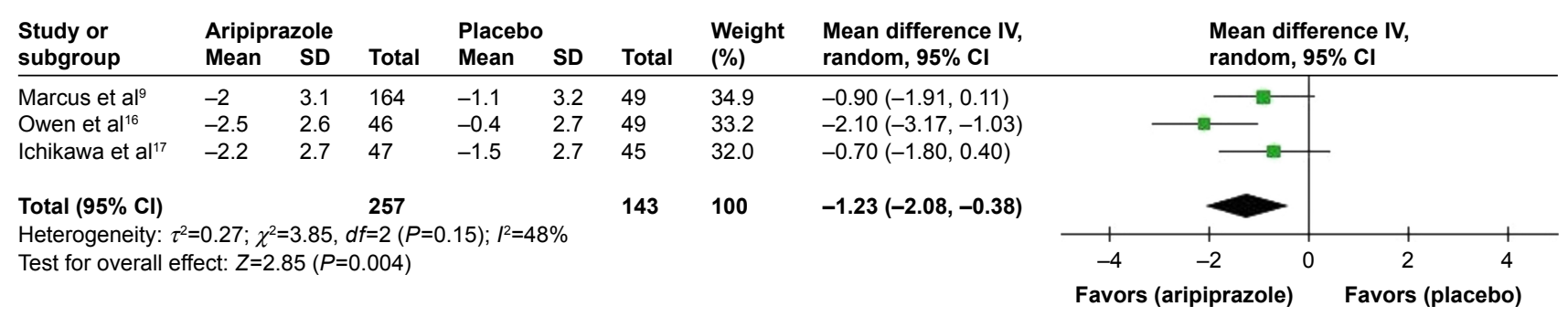

Figure 5 The forest plot of ABC-IS mean change scores from baseline $(95 \% \mathrm{Cl})$ of aripiprazole vs placebo in ASD in children and adolescents.

Abbreviations: ABC-IS, Aberrant Behavior Checklist-Inappropriate speech; ASD, autism spectrum disorder; df, degrees of freedom; IV, inverse variance.

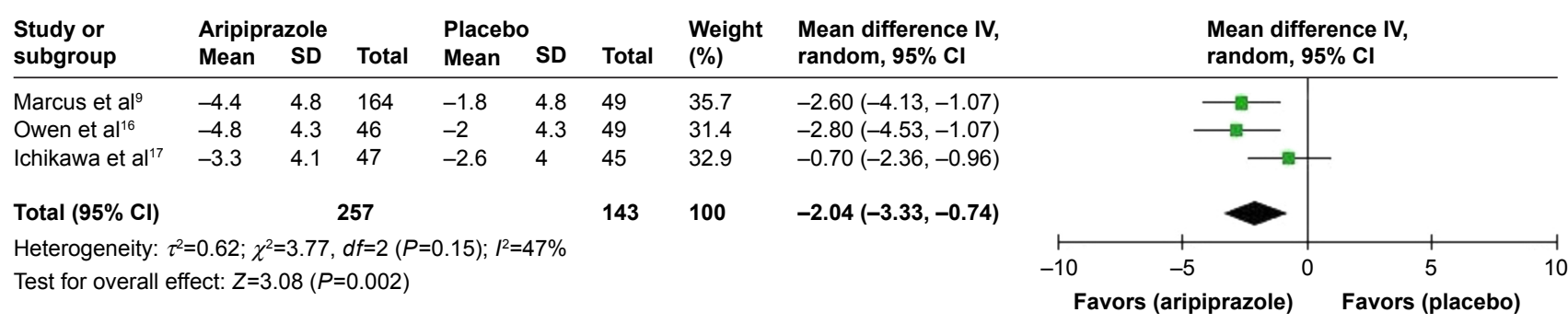

Figure 6 The forest plot of ABC-S mean change scores from baseline $(95 \% \mathrm{Cl})$ of aripiprazole vs placebo in ASD in children and adolescents.

Abbreviations: ABC-S, Aberrant Behavior Checklist-Stereotype behavior; ASD, autism spectrum disorder; $\mathrm{df}$, degrees of freedom; IV, inverse variance.

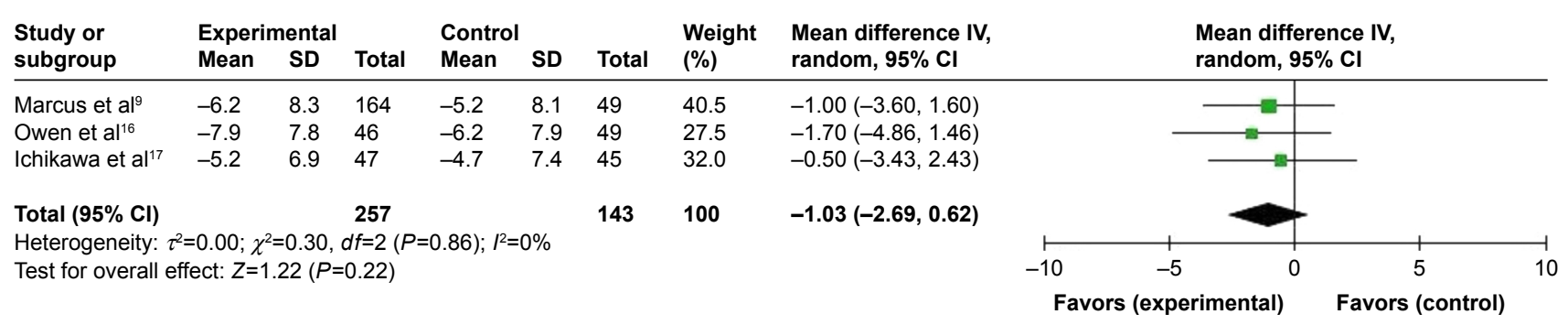

Figure 7 The forest plot of ABC-SW mean change scores from baseline $(95 \% \mathrm{Cl})$ of aripiprazole vs placebo in ASD in children and adolescents.

Abbreviations: ABC-SW, Aberrant Behavior Checklist-Lethargy/social withdrawal; ASD, autism spectrum disorder; $d f$, degrees of freedom; IV, inverse variance.

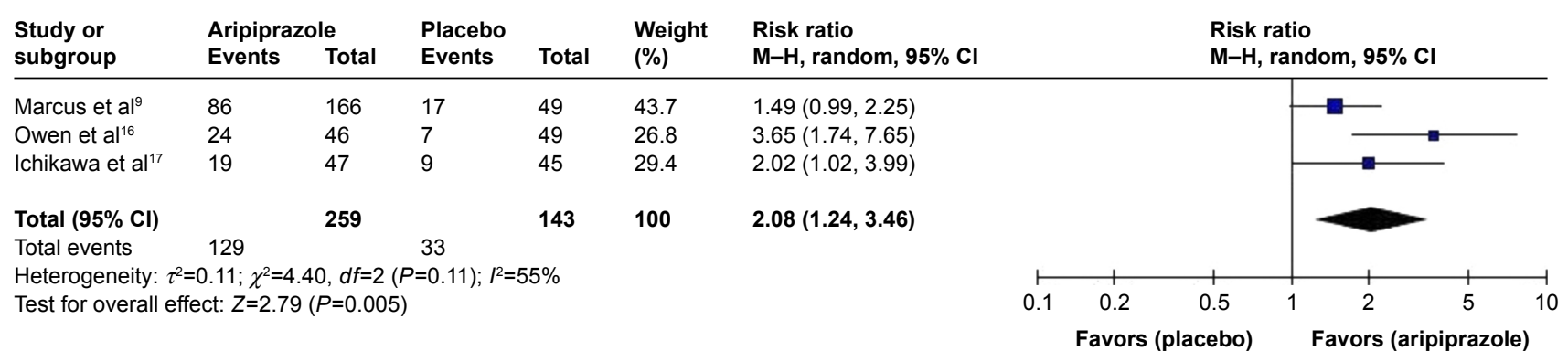

Figure 8 The forest plot of comparison of relative risk $(95 \% \mathrm{Cl})$ for response rate of aripiprazole vs placebo in ASD in children and adolescents.

Abbreviations: ASD, autism spectrum disorder; $d f$, degrees of freedom; $M-H$, Mantel-Haenszel test. 


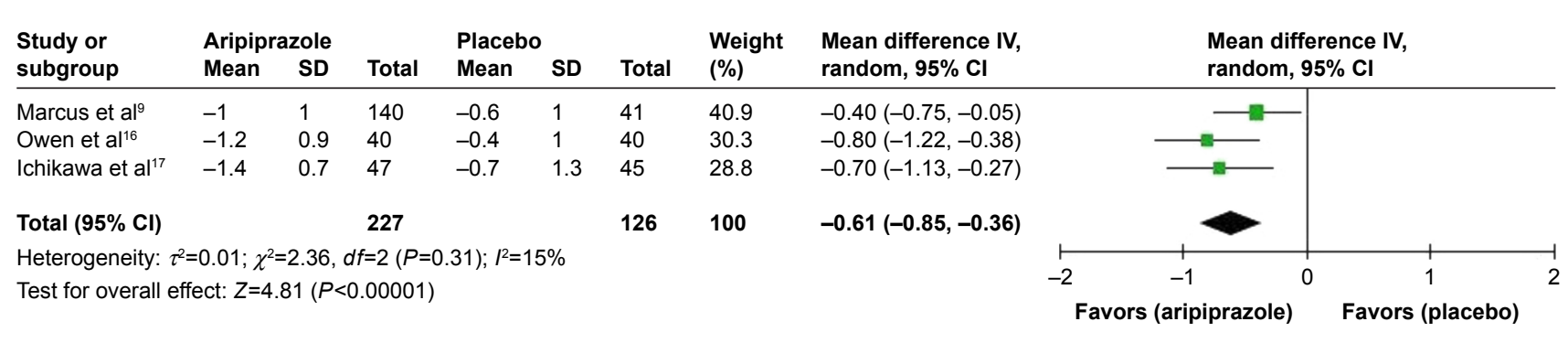

Figure 9 The forest plot of CGI-S mean change scores from baseline $(95 \% \mathrm{Cl})$ of aripiprazole vs placebo ASD in children and adolescents. Abbreviations: ASD, autism spectrum disorder; CGI-S, Clinical Global Impression-Severity; df, degrees of freedom; IV, inverse variance.

speech and stereotypic behavior in children and adolescents with ASD. Unfortunately, it could not improve the social withdrawal in such patients. Relying on an ABC-I measurement, the pooled response rate was $50 \%$. According to the response rate, the NNT of four indicates that one in every four children and adolescents with ASD benefits from aripiprazole in treatment of irritability. The review found that incidence of sedation was common in aripiprazole, while the extrapyramidal side effects and headache in aripiprazole were comparable to placebo. Interestingly, changed level of prolactin from baseline more significantly decreased in aripiprazole-treated group than placebo-treated group. Based on some metabolic profiles, number of decreased appetite patient was significantly higher in aripiprazole-treated group, while increase appetite did not differ. However, mean change of weight gain had significantly been greater in aripiprazole-treated group. The incidences of abnormal fasting triglyceride and serum glucose in aripiprazole were not different from those of placebo. Considering discontinuation rates, the acceptability of aripiprazole in the treatment of ASD was better than that of placebo, while its tolerability was comparable to placebo.

Antipsychotics have used in the treatment of various symptoms in ASD children and adolescents. According to previous evidence, haloperidol is able to decrease some behavioral problems and increase discrimination learning in childhood autism. ${ }^{6,710}$ In addition to a conventional antipsychotic drug, an atypical antipsychotic such as risperidone has illustrated its efficacy and tolerability in ASD treatment. Recent evidence indicated that risperidone has shown its efficacy over haloperidol in terms of reduction of behavioral symptoms and impulsivity, and improvement of language skills, sensory motor skill and social relationship skills. ${ }^{28-30}$ Similarly, some evidence also suggested that aripiprazole has been effective in the treatment of children and adolescents with ASD., 916,17

Generally, use of antipsychotics in children and adolescents should concern the safety and serious adverse events. Previous evidences have noted the adverse events of typical antipsychotics, including, cardiac risk, extrapyramidal side effects, high level of prolactin, and sedative effects. ${ }^{31,32}$ However, atypical antipsychotics, serotonin-dopamine antagonists, have shown the additional risk of metabolic syndrome. ${ }^{31}$ Additionally, the concern of QTc prolongation with antipsychotics has been reported in several studies until suggesting the ECG initial evaluation and monitoring for patients having the cardiac risk. ${ }^{33}$ Based on previous study, although the efficacy and safety of aripiprazole and risperidone in the treatment of ASD children and adolescents are comparable, ${ }^{34}$ possibly interchangeable in the treatment of such patients aripiprazole may more preference in patients who have to avoid those side effects, especially cardiovascular side effects, metabolic syndrome and prolactinemia.

According to previous evidences, an acceptability of antipsychotics such as risperidone was not better than the placebo, ${ }^{8,11,35}$ although the present review has shown that

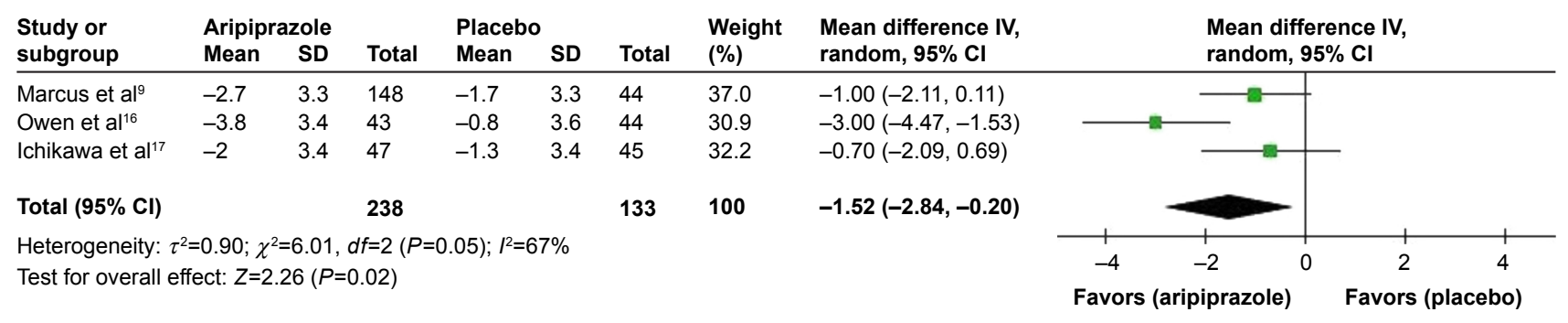

Figure 10 The forest plot of CY-BOCS mean change scores from baseline $(95 \% \mathrm{Cl})$ of aripiprazole vs placebo in ASD in children and adolescents. Abbreviations: ASD, autism spectrum disorder; CY-BOCS, Children's Yale-Brown Obsessive Compulsive Scale; $d f$, degrees of freedom; IV, inverse variance. 


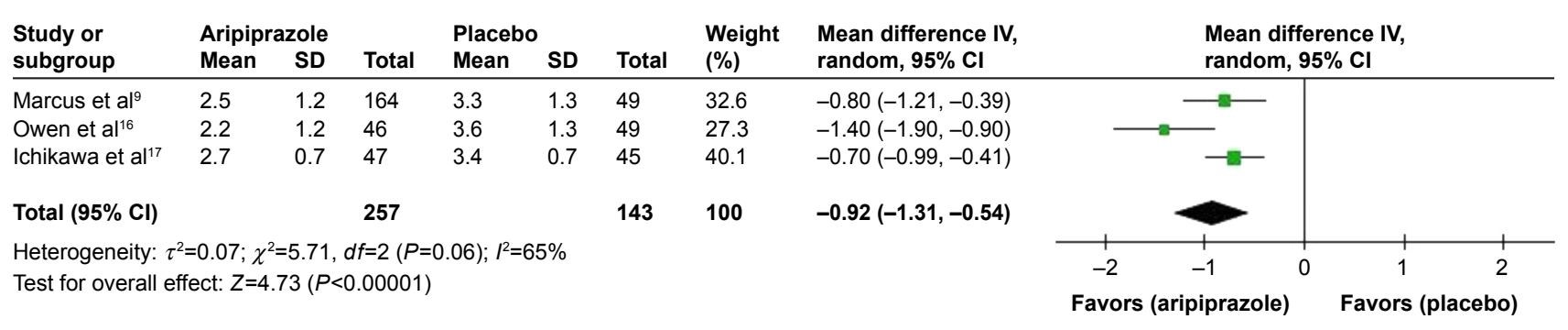

Figure II The forest plot of CGI-I mean end scores from baseline ( $95 \% \mathrm{Cl})$ of aripiprazole vs placebo in ASD in children and adolescents. Abbreviations: ASD, autism spectrum disorder; CGI-I, Clinical Global Impression-Improvement; df, degrees of freedom; IV, inverse variance.

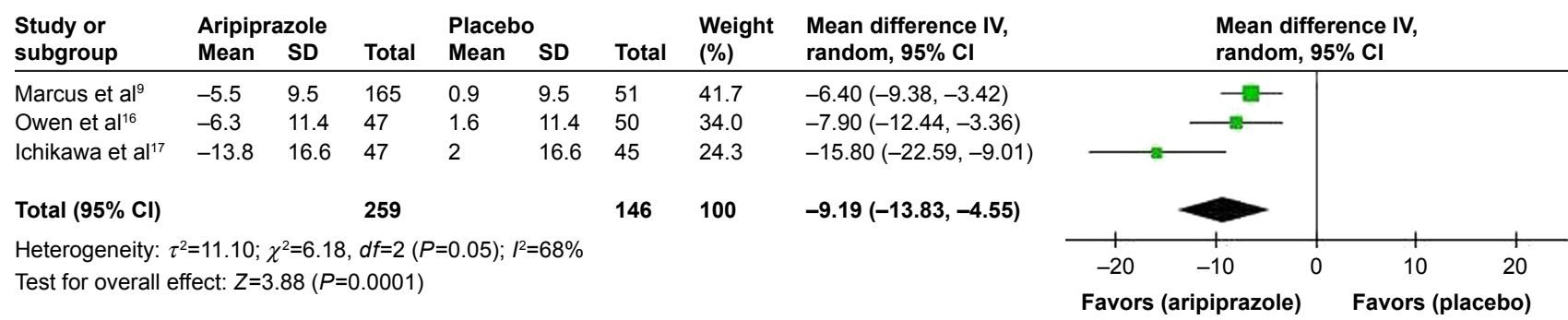

Figure 12 The forest plot of comparison of mean change scores for prolactin level from baseline $(95 \% \mathrm{Cl})$ of aripiprazole vs placebo in autism spectrum disorder in children and adolescents.

Abbreviations: $d f$, degrees of freedom; IV, inverse variance.

acceptability of aripiprazole, measured by the overall discontinuation rate, is greater than placebo in the treatment of ASD in children and adolescents. Similarly to risperidone, the tolerability of aripiprazole as measured in the discontinuation rate due to adverse events was not different from placebo in such treatment. ${ }^{8,11,35}$ In addition to its efficacy, aripiprazole may be considered in the treatment of ASD in children and adolescents since it has more acceptability and tolerability.

\section{Limitations}

Initially, a limited number of included RCTs may decrease the power of this meta-analysis. Secondly, since all eligible RCTs were financially supported by a patent holding company of aripiprazole, interpretation should be cautious. Finally, the test of funnel plot to define asymmetry could not be carried out because of a small number of included studies; ${ }^{24}$ therefore, publication bias could to be excluded.

\section{Conclusion}

Aripiprazole is efficacious in the acute treatment of irritability, hyperactivity/noncompliance, inappropriate speech and stereotypic behavior in children and adolescents with ASD. Unfortunately, it could not improve the social withdrawal in such patients. However, it is reasonably safe, more acceptable and well tolerable in such treatments. In addition to its efficacy in ASD children and adolescents, aripiprazole has shown low risk of adverse events, particularly in cardiovascular, metabolic and hyperprolactinemic side effects. Further well-defined and large sample size studies should be conducted to confirm those findings.

\section{Acknowledgments}

This meta-analysis received partially financial support from Chiang Mai University, Thailand. We also thank volunteers who carried out the work in the schools. NM and BM are joint first authors.

\section{Disclosure}

NM received travel reimbursement from Lundbeck and Pfizer. BM received honoraria and/or travel reimbursement from Lundbeck, Pfizer and Servier. SS received honoraria from Thai-Otsuka and Janssen-Cilag. MS received honoraria from Sumitomo Dainippon Pharma and Lundbeck. NM and $\mathrm{BM}$ are husband and wife. The other authors report no conflicts of interest in this work.

\section{References}

1. Schreibman L. Intensive behavioral/psychoeducational treatments for autism: research needs and future directions. J Autism Dev Disord. 2000;30(5):373-378.

2. Ospina MB, Krebs Seida J, Clark B, et al. Behavioural and developmental interventions for autism spectrum disorder: a clinical systematic review. PLoS One. 2008;3(11):e3755.

3. Spreckley M, Boyd R. Efficacy of applied behavioral intervention in preschool children with autism for improving cognitive, language, and adaptive behavior: a systematic review and meta-analysis. $J$ Pediatr. 2009;154(3):338-344. 
4. Masi A, DeMayo MM, Glozier N, Guastella AJ. An Overview of Autism Spectrum Disorder, Heterogeneity and Treatment Options. Neurosci Bull. 2017;33(2):183-193.

5. Béhérec L, Quilici G, Rosier A, Gerardin P, Campion D, Guillin O. Pharmacological treatments in patients with pervasive developmental disorders: A review. Encephale. 2014;40(2):188-196.

6. Anderson LT, Campbell M, Grega DM, Perry R, Small AM, Green WH. Haloperidol in the treatment of infantile autism: effects on learning and behavioral symptoms. Am J Psychiatry. 1984;141(10):1195-1202.

7. Anderson LT, Campbell M, Adams P, Small AM, Perry R, Shell J. The effects of haloperidol on discrimination learning and behavioral symptoms in autistic children. J Autism Dev Disord. 1989;19(2):227-239.

8. Mccracken JT, McGough J, Shah B, et al. Risperidone in children with autism and serious behavioral problems. $N$ Engl J Med. 2002; 347(5):314-321.

9. Marcus RN, Owen R, Kamen L, et al. A placebo-controlled, fixeddose study of aripiprazole in children and adolescents with irritability associated with autistic disorder. J Am Acad Child Adolesc Psychiatry. 2009;48(11):1110-1119.

10. Campbell M, Anderson LT, Small AM, Perry R, Green WH, Caplan R. The effects of haloperidol on learning and behavior in autistic children. J Autism Dev Disord. 1982;12(2):167-175.

11. Shea S, Turgay A, Carroll A, et al. Risperidone in the treatment of disruptive behavioral symptoms in children with autistic and other pervasive developmental disorders. Pediatrics. 2004;114(5):e634-e641.

12. Troost PW, Lahuis BE, Steenhuis MP, et al. Long-term effects of risperidone in children with autism spectrum disorders: a placebo discontinuation study. J Am Acad Child Adolesc Psychiatry. 2005;44(11): $1137-1144$.

13. Nagaraj R, Singhi P, Malhi P. Risperidone in children with autism: randomized, placebo-controlled, double-blind study. J Child Neurol. 2006;21(6):450-455.

14. El-Sayeh HG, Morganti C. Aripiprazole for schizophrenia. Cochrane Database Syst Rev. 2004;2:CD004578.

15. Li DJ, Tseng PT, Stubbs B, et al. Efficacy, safety and tolerability of aripiprazole in bipolar disorder: An updated systematic review and meta-analysis of randomized controlled trials. Prog Neuropsychopharmacol Biol Psychiatry. 2017;79(Pt B):289-301.

16. Owen R, Sikich L, Marcus RN, et al. Aripiprazole in the treatment of irritability in children and adolescents with autistic disorder. Pediatrics. 2009;124(6):1533-1540.

17. Ichikawa H, Mikami K, Okada T. Aripiprazole in the Treatment of Irritability in Children and Adolescents with Autism Spectrum Disorder in Japan: A Randomized, Double-blind, Placebo-controlled Study. Child Psychiatry Hum Dev. 2017;48(5):796-806.

18. Higgins JPT, Altman DG, Sterne JAC; on behalf of the Cochrane Statistical Methods Group and the Cochrane Bias Methods Group. Assessing risk of bias in included studies. In: Higgins JPT, Green S, editors. Cochrane Handbook for Systematic Reviews of Interventions. Version 5.1.0 [updated March 2011]. The Cochrane Collaboration; 2011.

19. Aman MG, Singh NN, Stewart AW, Field CJ. The aberrant behavior checklist: a behavior rating scale for the assessment of treatment effects. Am J Ment Defic. 1985;89(5):485-491.

20. Aman MG, Singh NN, Stewart AW, Field CJ. Psychometric characteristics of the aberrant behavior checklist. Am J Ment Defic. 1985;89(5): $492-502$.
21. Cipriani A, Furukawa TA, Salanti G, et al. Comparative efficacy and acceptability of 12 new-generation antidepressants: a multipletreatments meta-analysis. Lancet. 2009;373(9665):746-758.

22. Papakostas GI. Tolerability of modern antidepressants. J Clin Psychiatry. 2008;69 Suppl E1:8-13.

23. Wiebe N, Vandermeer B, Platt RW, Klassen TP, Moher D, Barrowman NJ. A systematic review identifies a lack of standardization in methods for handling missing variance data. J Clin Epidemiol. 2006;59(4):342-353.

24. Sterne JAC, Egger M, Moher D, Biases AR. Addressing reporting biases. In: Higgins JPT, Green S, editors. Cochrane Handbook for Systematic Reviews of Interventions. Version 5.1.0 [updated March 2011]. The Cochrane Collaboration; 2011. Available from: http://www. cochrane-handbook.org

25. Jordan I, Robertson D, Catani M, Craig M, Murphy D. Aripiprazole in the treatment of challenging behaviour in adults with autism spectrum disorder. Psychopharmacology. 2012;223(3):357-360.

26. Findling RL, Mankoski R, Timko K, et al. A randomized controlled trial investigating the safety and efficacy of aripiprazole in the long-term maintenance treatment of pediatric patients with irritability associated with autistic disorder. J Clin Psychiatry. 2014;75(1):22-30.

27. Mankoski R, Stockton G, Manos G, et al. Aripiprazole treatment of irritability associated with autistic disorder and the relationship between prior antipsychotic exposure, adverse events, and weight change. JChild Adolesc Psychopharmacol. 2013;23(8):572-576.

28. Miral S, Gencer O, Inal-Emiroglu FN, Baykara B, Baykara A, Dirik E. Risperidone versus haloperidol in children and adolescents with AD: a randomized, controlled, double-blind trial. Eur Child Adolesc Psychiatry. 2008;17(1):1-8.

29. Gencer O, Emiroglu FN, Miral S, Baykara B, Baykara A, Dirik E. Comparison of long-term efficacy and safety of risperidone and haloperidol in children and adolescents with autistic disorder. An open label maintenance study. Eur Child Adolesc Psychiatry. 2008;17(4): 217-225.

30. Maneeton N, Maneeton B, Putthisri S, Woottiluk P, Narkpongphun A, Srisurapanont M. Risperidone for children and adolescents with autism spectrum disorder: a systematic review. Neuropsychiatr Dis Treat. 2018;14:1811-1820.

31. De Hert M, Detraux J, van Winkel R, Yu W, Correll CU. Metabolic and cardiovascular adverse effects associated with antipsychotic drugs. Nat Rev Endocrinol. 2011;8(2):114-126.

32. Zhang JP, Gallego JA, Robinson DG, Malhotra AK, Kane JM, Correll CU. Efficacy and safety of individual second-generation vs. first-generation antipsychotics in first-episode psychosis: a systematic review and meta-analysis. Int $J$ Neuropsychopharmacol. 2013;16(6): $1205-1218$.

33. Shah AA, Aftab A, Coverdale J. QTc prolongation with antipsychotics: is routine ECG monitoring recommended? J Psychiatr Pract. 2014; 20(3):196-206.

34. Ghanizadeh A, Sahraeizadeh A, Berk M. A head-to-head comparison of aripiprazole and risperidone for safety and treating autistic disorders, a randomized double blind clinical trial. Child Psychiatry Hum Dev. 2014;45(2):185-192.

35. Kent JM, Kushner S, Ning X, et al. Risperidone dosing in children and adolescents with autistic disorder: a double-blind, placebo-controlled study. J Autism Dev Disord. 2013;43(8):1773-1783.
Neuropsychiatric Disease and Treatment

\section{Publish your work in this journal}

Neuropsychiatric Disease and Treatment is an international, peerreviewed journal of clinical therapeutics and pharmacology focusing on concise rapid reporting of clinical or pre-clinical studies on a range of neuropsychiatric and neurological disorders. This journal is indexed on PubMed Central, the 'PsycINFO' database and CAS,

\section{Dovepress}

and is the official journal of The International Neuropsychiatric Association (INA). The manuscript management system is completely online and includes a very quick and fair peer-review system, which is all easy to use. Visit http://www.dovepress.com/testimonials.php to read real quotes from published authors. 